\title{
Emergencia, declive y reconstrucción del concepto de sociedad civil. Pautas para análisis futuros *
}

\author{
ANDREW ARATO \\ New School for Social Research, New York
}

El concepto de sociedad civil ha cobrado especial relevancia en el ámbito de la teoría política de la democracia por su potencialidad analítica para el estudio de las transiciones desde regímenes dictatoriales a otros democráticos, así como para identificar nuevas esferas susceptibles de profundización democrática en el seno de las democracias realmente existentes. Toman- do como base empírica de referencia las experiencias democratizadoras acaecidas en Europa Central y del Este, en el artículo se pasa revista a las principales objeciones teóricas al uso contemporáneo del concepto de sociedad civil y se apuntan algunas áreas de investigación que contribuirían al proyecto permanente de ensanchamiento democrático.

El concepto de sociedad civil fue resucitado en círculos neomarxistas críticos del socialismo autoritario hace aproximadamente veinte años, invirtiendo así una de las premisas fundamentales de Marx y convirtiéndose en "postmarxistas». Es evidente que dicho concepto podria haber resurgido (bien sea bajo una forma «neo» o «post») a partir de la herencia intelectual de Montesquieu, Burke, Tocqueville, o incluso de Laski, Parsons u otros. No por casualidad, los trabajos pioneros en esta reactivación (a cargo de autores como Kolakowski, Mlynar, Vajda y Michnik en el este; Habermas, Lefort y Bobbio en el oeste; y Weffort, Cardoso y O'Donnell en el sur) hundían sus raíces en tradiciones intelectuales similares, occidentales o neomarxistas. A juicio de todos ellos, Hegel, el joven Marx y Gramsci representaban el vínculo para la utilización contemporánea del concepto de sociedad civil y de la dicotomía Estado-sociedad civil que fueron, de modos diferentes, prácticamente universales en el siglo XIX, pero que casi desaparecieron de las ciencias sociales y políticas, así como de la filosofía del siglo XX. En su etapa inicial, el marxismo occidental profundizó cn la filosofía social de Marx mediante una vuclta a sus raíces filosóficas, al tiempo que ponía de manifiesto la relación entre una lectura hegeliana de Marx y trabajos específicos de la filosofia y teoría social no marxista (autores

* Traducción de Jesús Casquete. 
como Weber, Simmel, Croce y Freud entre otros). En este momento, conceptos como alienación, fetichismo, reificación, racionalización, represión y praxis ocupaban un lugar central. Al menos en apariencia, la revitalización del concepto de sociedad civil era una tarea inscrita en el mismo proyecto. Su utilización en los escritos del joven Marx justificaba tanto una revisión crítica como la apropiación de ideas de otra serie de pensadores no marxistas, desde Tocqueville a Hannah Arendt. Sin embargo, en esta ocasión, en lugar de utilizar lo mejor de Marx, la estrategia conceptual centrada en la sociedad civil acudió a Gramsci para dar la vuelta incluso al joven Marx. El objetivo no era otro que dar con un concepto que evidenciase, autocríticamente, el origen temprano del giro autoritario marxista, un concepto que proporcionase el nexo de unión $a b$ ovo con el socialismo de Estado, con la política «comunista». En suma, la voluntad del joven Marx de superar la separación y diferenciación entre Estado y sociedad civil es interpretada ahora como el origen y la justificación de la estatización maxista de todos los aspectos de la realidad social.

En un principio, el fruto de la iniciativa se limitó a una nueva (aunque difícilmente anticipable) conceptualización del totalitarismo tanto en Francia como en otros dos paises, Polonia y Hungría, que no eran «totalitarios». Éste era un comienzo desafortunado, destinado a crear poco más que un concepto novedoso, crítico y polémico. El sorprendente éxito histórico de la reactivación del concepto de sociedad civil, proceso en el que he tenido el honor de participar, se debió a su capacidad de anticipar, intelectualizar y converger en una nueva estrategia reformista radical, evolucionista y dualista para la transformación de regímenes dictatoriales, primero en el este de Europa e inmediatamente después en Latinoamérica. Esta estrategia se basaba en las ideas de autoorganización de la sociedad, en la reconstrucción de vínculos sociales al margen del Estado autoritario y en la apelación a una esfera pública independiente no mediatizada por ningún Estado ni partido. Utilizado en este sentido, el concepto de sociedad civil se convirtió en un punto de referencia inexcusable, primero en Polonia, durante un tiempo en Francia, y después (seguramente debido a la mediación de intelectuales franceses) en Brasil, para continuar con debates de ámbito geográfico más amplio en Europa del Este y en Latinoamérica tras los éxitos del sindicato polaco Solidaridad y de la abertura. Cuando menos en Hungría, Checoslovaquia, Yugoslavia (iespecialmente en Eslovenia!), Rusia, Chile, Argentina y México, una mayor elaboración del concepto de sociedad civil y la formación de estrategias políticas fueron procesos estrechamente vinculados a lo largo de la década de los ochenta. Entretanto, algunos procesos de transición que tuvieron lugar con anterioridad (en particular los casos de España y de Grecia), así como los intentos exitosos de estabilización de sistemas autoritarios (sobre todo en China) fueron interpretados tanto por participantes como por observadores apelando a varias versiones del concepto de sociedad civil. Al menos en aquellos lugares donde la transición fue exitosa y donde la estrategia intelectual desempeñó un papel político relevante, el 
concepto de sociedad civil se tornó en moneda de uso corriente en medios periodísticos. Esto es especialmente cierto en el caso de Hungría. Finalmente, hoy día asistimos a una amplia discusión en numerosos países occidentales con sociedades civiles consolidadas en los que el objetivo es encontrar nuevos espacios potenciales para la democratización de las democracias realmente existentes. Teóricos como Habermas, Lefort y Bobbio exploraron tempranamente dicha posibilidad, y Jean Cohen y yo mismo hemos hecho una aportación a este debate con nuestra obra Civil Society and Political Theory (1992) y con ensayos publicados en la década precedente.

Ahora, varios años después de la publicación de nuestra obra, el panorama ha variado sustancialmente. Debo admitir que muchas de las nuevas cuestiones que han emergido me han venido preocupando durante largo tiempo. En primer lugar, en el ámbito de la sociología general, resulta evidente cuestionar la idea de que algo inexistente (la sociedad civil bajo regímenes autoritarios) pueda contribuir a la liberación de la sociedad. Incluso si excluyésemos como totalitarias a las sociedades de tipo soviético, especialmente Polonia y Hungría, de ningún modo carecían de sociedades civiles en el sentido de esferas de la vida social institucionalizadas y legalmente diferenciadas, tal y como fueron definidas por Hegel y Tocqueville. Por lo tanto, debemos distinguir conceptualmente entre redes sociales, solidaridades y relaciones informales de las estructuras de la sociedad civil más formalizadas e institucionalizadas. Sin embargo, los movimientos, iniciativas, asociaciones y públicos autoorganizados, al poner lo social en movimiento, eran diferentes tanto de las redes latentes surgidas de la autonomía social como de las sociedades civiles institucionalizadas tal y como las conocemos en Occidente. En consecuencia, en lugar de utilizar un único concepto, uno se encuentra ante la tarea de emplear tres conceptos diferentes para luego darles una unidad histórica. En nuestra obra antes citada, nosotros emprendemos parcialmente esta tarea al distinguir la sociedad civil como movimiento de la sociedad civil como institución, siendo la primera una especie de sociedad civil constituyente de la última, la versión constituida e institucionalizada. No obstante, la relación temporal entre ambas formas no resulta del todo evidente. Es innegable que ciertas formas de institucionalización posibilitan la reaparición de movimientos e iniciativas que a su vez pueden o no tener como objetivo rupturas institucionales. Nuestra distinción entre revolución y desobediencia civil capta esta diferencia. La desobediencia civil, estrechamente vinculada a los movimientos e iniciativas sociales, representa el límite último de la acción colectiva en el seno de la sociedad civil, siendo distinta de la sociedad civil organizada en forma de movimiento. 
Sin embargo, opino que hoy en día, junto con la distinción entre sociedad civil como movimiento y sociedad civil como institución, necesitamos reintroducir bien el equivalente de lo social en Durkheim bien la noción de redes sociales tal y como ha sido tratada en la más reciente literatura sobre movimientos sociales. No obstante, a pesar de los hallazgos realizados por estos análisis sobre los vínculos entre los movimientos y lo social, aún carecemos de una sociologia del derecho lo suficientemente sofisticada como para acometer una tarea similar entre lo social y la sociedad civil institucionalizada.

En segundo lugar, y desde una perspectiva política, la experiencia de la transición a la democracia en los países con movimientos e iniciativas suciales más dinámicos nos ha enseñado que la sociedad civil por sí misma (en el marco de una estrategia autolimitante e incluso de una estrategia revolucionaria) no puede acometer un cambio en el régimen. Sabemos desde hace tiempo que, en el curso de la batalla física por el poder acaecido en todas las revoluciones modernas, la acción tiende a estar concentrada en unas élites que son (o se transforman en) hostiles a la autoorganización desde abajo. También sabemos que en las transiciones posrevolucionarias (revoluciones contra la Revolución, pero sin ser necesariamente contrarrevolucionarias) se produce un desplazamiento de la acción hacia las élites políticas, las contraćlites o los partidos políticos. Sólo ellos están capacitados para llevar a cabo las estratégicas misiones de negociación y diseño de pactos con los antiguos detentadores del poder. Tal y como ilustra el modelo de teoría de juegos de cuatro factores elaborado por Adam Przeworski, la sociedad civil puede ser considerada un actor durante dicho proceso. Mas para las élites políticas (así como para el éxito de las negociaciones) es importante que la sociedad civil se desmovilice para poder alcanzar un pacto que culmine en elecciones democráticas.

Siguiendo una sugerencia de Alfred Stepan, en nuestra obra aceptamos la diferenciación entre sociedad civil y política (ya presente en la obra de Tocqueville) para afrontar los dos niveles de la vida asociativa presentes en toda transición y, tal y como lo vemos ahora, en las sociedades democráticas en general. A diferencia de la mayor parte de la literatura sobre transiciones a la democracia, a nuestro juicio la transferencia de protagonismo desde la sociedad civil a la política durante el cambio de régimen no implica inexorablemente la total desmovilización y atomización de la esfera civil. Más aún, pensamos que tanto la estabilización de la democracia como las expectativas futuras de democratización dependen del desarrollo de una compleja relación a dos bandas entre lo civil y lo político. De modo parecido, es preciso distinguir entre una sociedad económica basada en formas de propiedad y asociaciones meramente económicas, una sociedad política basada en el sufragio y los partidos políticos y una sociedad civil basada en el derecho a la comunicación y las asociaciones y movimientos civiles. El resultado final es un modelo compuesto de cinco elementos con el que hemos reemplazado el dualismo convencional entre Estado y sociedad. Desafortunadamente, no podemos afirmar que hayamos resuelto 
el problema de las formas de interacción deseables y posibles entre los cinco niveles, problema en cuya resolución creemos que descansa el futuro de la democracia.

En tercer lugar, en el terreno metodológico del análisis conceptual, el concepto de sociedad civil permanece infestado de ambigüedades. Incluso después de distinguir la sociedad civil de la política y la económica (paso en sí mismo controvertido), no quedan claras las implicaciones de la sociedad civil. Nosotros mismos siempre nos hemos referido a asociaciones y públicos cuya estabilidad está garantizada por una serie de derechos fundamentales (de asociación, asamblea, expresión, prensa y privacidad), operando bajo una lógica normativa de acción y coordinación comunicativa en el sentido habermasiano. Siguiendo una sugerencia del primer Habermas, nosotros subrayamos la pluralidad de públicos. Esto nos conduce al problema evidente de que existen públicos en las esferas diferenciadas de la sociedad (en la ciencia, el arte, la ley, la religión, etc.) en los que la admisión no puede ser democrática. $Y$ sin embargo, es en estas esferas donde tienen lugar procesos de comunicación social relevante. Además, el estudio de las asociaciones no se limita a un único nivel de análisis: el tamaño, la lógica, el alcance espacial y temporal, así como el papel político desempeñado por los grupos informales, las organizaciones de expertos y de profesionales, los grupos de presión, etc., son todos aspectos diferentes. A su vez, todos estos grupos y asociaciones difieren de los movimientos sociales en varios aspectos: estos últimos son internamente diferentes dependiendo de su nivel de organización, del número de temas sobre los que centran su acción, el papel que juegan en su configuración el interés, la formación de identidad y la necesidad de autoexpresión, etc. Evidentemente, existe una literatura sociológica especializada que afronta diferentes aspectos de la vida grupal y de movimiento, y debería existir otra literatura que se enfrentase con los diferentes públicos. La pregunta es inevitable: ¿por qué nos referimos a esta compleja amalgama conceptual con el término sociedad civil?

Por supuesto que podemos plantearnos la misma pregunta acerca de la economía y del Estado. La diferencia estriba en que, en estos casos, los conceptos de dinero y de poder (político) delimitan los perfiles de la diferenciación. En tanto que la lógica de la acción y coordinación comunicativa elaborada por Habermas ha resuelto a nuestro juicio este problema para el caso de la sociedad civil, al volver a nuestro modelo de cinco elementos nuevos problemas afloran. ¿Pueden la sociedad política y económica, sus parlamentos y juntas de gobierno, excluir por ejemplo la libre comunicación? ¿Pueden las asociaciones de la sociedad civil excluir el dinero y el poder? En caso de respuesta negativa, iestamos haciendo frente a un problema de principio o a uno de grado a medida que nos desplazamos de la sociedad civil a la política y viceversa? En principio, utilizar la categoría de sociedad civil en nuestro sentido omnicomprensivo recoge dicha diferencia. En consecuencia, la primacía de la acción y coordinación comunicativa en una vasta serie de instituciones representa el punto de par- 
tida que dota de unidad a la categoría de sociedad civil. Desafortunadamente, nosotros tan sólo hemos sido capaces de ilustrar este problema a través de una serie limitada de ejemplos. Uno de ellos hace referencia a los límitcs temporales, sociales y sustantivos de la comunicación parlamentaria comparada con los procesos de comunicación abiertos y no constreñidos que son posibles en el seno de las familias, las universidades o los medios de comunicación social. Otro ejemplo es la naturaleza evidentemente patológica de las familias, periódicos, universidades, etc, cuyo objetivo principal (en lugar de secundario) es la acumulación de poder o dinero para sus integrantes, en competencia con los partidos políticos o las juntas de administración de las empresas.

Sin embargo, la unidad de la sociedad civil es aparente tan sólo desde un punto de vista normativo. Existen numerosas asociaciones de la sociedad civil en las que el dinero y el poder son el factor fundamental, del mismo modo que existen partidos políticos que actúan como movimientos sociales (por ejemplo, incorporando lógicas democráticas antiburocráticas y directas). En este último caso, argumentos funcionales con predicciones empíricas especificas (como la ley de hierro de la oligarquía de Michels) constituyen una buena prueba de las dificultades inherentes a una labor tal. Así pues, podemos afirmar que si las instituciones de la sociedad política no están inicialmente diferenciadas en cuanto tales, entonces están destinadas o bien al fracaso o bien a su transformación en una dirección estratégicamente relevante. Sin embargo, no se puede afirmar lo mismo desde el punto de vista de la sociedad civil, a pesar de que a partir de un cierto umbral (cuya ubicación no puede ser demostrada a priori) la «colonización del mundo de la vida» podría también derivar en una ruptura de la integración social. En este contexto, sólo disponemos de un criterio normativo y crítico en cierto grado contrafactual.

En cuarto lugar, existen problemas en la teoría normativa con el concepto de sociedad civil. A este respecto, podemos preguntarnos cuál es la aportación al liberalismo y a la teoría democrática de una concepción que engloba aspectos liberales y democráticos (derechos y participación). Un problema similar surge con la desdiferenciación aparente entre las perspectivas democrática liberal y republicana en relación con la categoría central de esfera pública. Por un lado, se puede argumentar que, aislados analíticamente, el liberalismo, la teoría democrática y el republicanismo pueden desarrollar sus conceptos característicos de una manera más distintiva, rica y coherente. Por otro lado, no debemos restar importancia a las contradicciones entre estas perspectivas recurriendo a formas de conceptualización analíticamente menos diferenciadoras. Sin embargo, es evidente para nosotros que las tres perspectivas normativas sólo son contradictorias en algunas de sus interpretaciones específicas. El conccpto de sociedad civil contribuye decisivamente a interpretar de manera compatible las filosofías políticas liberales, democráticas e incluso republicanas.

Nuestro enfoque, consciente de las tensiones potenciales, apuesta por una síntesis entre las diferentes filosofías políticas. Sin duda, dicho enfoque depende 
de la creación conceptual cn los campos de la filosofía legal y política, todo ello sin pretender desplazar la reflexión filosófica. Por eso, el concepto de sociedad civil es demasiado empírico y sociológico, demasiado próximo al discurso de los actores políticos. Esto nos lleva a otra objeción quizá más seria. ¿No dcberiamos acaso distinguir las dimensiones normativas o filosóficas de las sociológicas o empíricas? Argumentos analíticos filosóficos como los neokantianos y similares precisarían de una distinción en este sentido; también una teoría sociológica de la diferenciación estricta entre subsistemas, incluidos los de la ciencia y la filosofia, necesitan distinguir entre ambas dimensiones. Sin embargo, por muy importante que pueda ser la diferenciación analítica desde un punto de vista puramente teórico, desde cl punto de vista de la acción es importante plantear cuestiones que vinculen diferentes esferas. En primer lugar, el desarrollo de la teoría política y de la teoría democrática pucden ser vistos como un fin en sí mismo. Pero desde el punto de vista de los actores, el problema principal se reficre a las posibilidades de institucionalización de fines normativos, que de cste modo se erigen en proyectos. E inversamente, en numerosos contextos empíricos, actores en busca de orientación deben remitirse tanto a diagnósticos realizados por las ciencias sociales como a argumentos normativos. Éstos serán relevantes para los actores sólo cuando se encuentren mediados por una teoría de rango medio que afronte los problemas de la posible institucionalización y que sea formulada en un lenguaje más cercano al de los actores. En ambos casos, la teoría de la sociedad civil proporciona un nexo de unión que permite la movilización empírica de conceptos normativos sin caer en excesos utópicos (que una teoría normativa no mediada sin duda produciría) ni tampoco en una relación acrítica con la realidad política empírica (que sería el resultado de abandonar por completo perspectivas normativas).

Por último, si bien asumimos parcialmente la diferenciación entre los subsistemas científico, filosófico y político, rechazamos la noción a la Luhmann de que no puede haber comunicación entre estas esferas. De hecho, nosotros insistimos en la posibilidad de comunicación entre todos los públicos expertos y especializados. Sin duda, dicha comunicación requiere la existencia de csferas públicas no diferenciadas y no expertas en las que la comunicación referida a problemas comunes pucde tener lugar. El mismo Luhmann reconoce la existencia de una esfera pública durante el período de la Ilustración. Estas esferas persisten hoy en día en los medios de comunicación y las universidades (por citar tan sólo dos contextos clave), aunque bajo formas menos totalizadoras y más complejas. La esfera pública es al mismo tiempo un componente y un presupuesto sociológico clave en la utilización de la categoría de sociedad civil hoy en día. Necesitamos profundizar aún más en el conocimicnto de su estructura y su relación con los públicos expertos y con los públicos de las sociedades política y económica. 
Hasta el momento hemos repasado las principales dificultades teóricas del uso del concepto de sociedad civil. También hemos sugerido algunas pautas para su resolución. Pero sería un grave error asumir que las críticas al uso del concepto de sociedad civil son tan sólo de carácter teórico. En los países centroeuropeos del antiguo bloque del Este, donde el concepto proporciona pautas para la acción política, muchas de las objeciones y críticas están políticamente motivadas. Y no estoy pensando ni en los defensores de un sistema autoritario de gobierno ni tampoco en los nostálgicos del régimen anterior. Los reparos más significativos proceden de los antiguos defensores del concepto empeñados en la liberación de la sociedad civil.

De acuerdo con la fórmula dualista para la reconstrucción de la sociedad civil, una sociedad unificada se organizaba contra un Estado-partido monolítico concebido como enemigo: «nosotros» contra «ellos». En este contexto, ha sido no sólo fácil sino hasta necesario que orientaciones idcológicas diferentes se agrupasen en un movimiento social unificado y autolimitado para participar en política. No sólo los universalistas, reformistas, radicales y socialdemócratas, sino también los nacionalistas, revolucionarios y liberales no tenían otra opción sino sumarse a la lucha por la fundación de plataformas institucionales para otros proyectos (a corto o largo plazo), siempre dentro de unos límites que no permitían la total consecución del programa político propio. Sin embargo, siempre hubo reservas del estilo de las que salieron a la luz en la esfera pública libre en Polonia tras el debilitamiento de Solidaridad: el programa orientado hacia la sociedad civil era demasiado colectivista a juicio de los liberales, demasiado cosmopolita para los nacionalistas, demasiado defensivo para los revolucionarios, demasiado liberal para los neomarxistas defensores de los intereses de clase, demasiado populista para los partidarios de la Realpolitik. Tras la desaparición del enemigo, todas estas corrientes se enzarzaron en una lucha fraticida de uno contra otro y contra los defensores y el programa de una sociedad civil democrática, proyecto que podría haber gozado de un consenso mínimo entre muchos de ellos. Por un lado, la aparición de una revuelta populista en contra del gobierno de Mazowiecki y del programa reformista de Balczerowicz y cl fenómeno Walesa y Tyminski y, por otro lado, la herencia de un sistema de partidos fragmentado, son las dos vertientes de un complejo en el que partidos sin esperanza de alcanzar un consenso fragmentan el espacio político, enfrentándose a una sociedad autodemocratizadora que, privada de canales de participación, se arroja cn brazos del populismo.

En Hungría, el programa orientado hacia la sociedad civil nunca se correspondió con un movimiento unificado. Por esta razón, la sociedad húngara después de los sucesos de $1956 \mathrm{se}$ ha comportado de un modo demasiado apático e individualista. Sin embargo, en una forma distinta y más sofisticada, la opo- 
sición demócrata húngara, dirigida por János Kis alrcdedor de la revista Beszélö, adoptó el modelo polaco de «reformismo radical», cuyo eje maestro apuntaba a la reconstrucción desde abajo de la sociedad civil y de una esfera pública independiente. Hasta 1988 surgieron numerosos grupos, formando una variedad de coaliciones compleja e interconectada, todas ellas bajo la bandera (bastante común en los países de la Europa del Este) de una sociedad civil democrática orientada hacia la democratización política y el establecimiento de una moderna economía de mercado. En las elecciones de marzo de 1990, un 55\% de la población dio su voto a partidos surgidos de esta tradición. Si estos partidos se hubiesen coaligado en un gobicrno de transición, Hungría atravesaría hoy una mejor situación, con un gobierno más fuerte, una cultura menos dividida, mejor encauzada en la ruta hacia la economía de mercado y probablemente con una socicdad civil menos amenazada.

No ocurrió así, en parte debido a deficiencias en la teoría política. En lugar de concentrarse en su propio proyecto y el modo de llevarlo a cabo, los participantes se centraron en el presente de Europa o en el pasado de Hungría como únicos referentes dignos de imitación. Pero, también en Hungría, algunos de los que en 1988 eran defensores de la sociedad civil cambiaron de posicionamiento, presentándose en 1990 con proyectos aparentemente incompatibles con ella. Considero que muchas de las reservas intelectuales al uso de la categoría de sociedad civil son reflejo de la incompatibilidad de estos proyectos. A juicio de los revolucionarios, partidarios de la purga y del castigo, la idea de una revolución autolimitada era demasiado pobre y la orientación hacia la sociedad civil demasiado legalista y gradualista. A juicio de los nuevos profesionales de la política, el mantener canales de comunicación abiertos con grupos ajenos a los partidos y parlamentos chocaba con su concepción de la democracia, derivada no tanto de los ideales occidentales como de la práctica elitista occidental de la democracia. Por decirlo con cierta dosis de cinismo, veían amenazado su monopolio de poder imaginado. Para los liberales, que se ven a sí mismos como burgueses, después de proclamar en sus panfletos la deseabilidad de una sociedad civil rica y plural (una sociedad de sindicatos, ecologistas, asociaciones de consumidores, etc.) como único contexto apropiado a una economía de mercado, luego la juzgan como un lujo sólo al alcance de las economías de mercado desarrolladas. Por el momento, opinan estos liberales, basta con una sociedad civil que garantice el derecho a la propiedad. Con este giro, se alían con los demócratas elitistas, para quiencs la política debe permanecer aislada de las influencias de la sociedad. Tampoco parecen ser conscientes de que el papel legitimatorio de unas elecciones democráticas es insuficiente para una población que atraviesa graves penurias económicas. Por otro lado, los nacionalistas están interesados en la comunidad imaginada del todo social, nutriéndose del pasado, y sin preocuparse por las comunidades reales que se enfrentan a los retos del siglo XXI. Sobre todo, tienen miedo de los valores postmaterialistas modernos asociados sobre todo 
a los nucvos movimientos sociales. Igual que los defensores de una política de clase, los nacionalistas canalizan la protesta social, advertida o inadvertidamente, en una dirección populista, tal y como hemos podido comprobar en el caso de un partido de clase húngaro, el Partido de los Pequeños Propietarios (FKGP) y en el del revitalizado sindicato ex-oficial (MSZOSZ) que ahora juega un papel decisivo en el Partido Socialista (MSzP).

Todos estos discursos políticos tienen en común que desplazan el discurso y política de la sociedad civil, y colocan en su lugar formas de pensamiento históricamente desacreditas. No obstante, su impacto conjunto ha alterado la línea principal de desarrollo del concepto de sociedad civil, sobre todo entre las élites intelectuales de países centroeuropeos como Hungria y Polonia. Ahora, incluso entre intelectuales con planteamientos socioliberales (antes en la oposición democrática), la utilización de la categoría de sociedad civil es esporádica y determinada por consideraciones tácticas. Incluso en la lucha que tuvo lugar en Hungría a favor de medios de comunicación libres, la categoría de sociedad civil podría haber jugado un papel central, pero finalmente no adquirió la relevancia que podría haberse esperado tan sólo unos años antes.

\section{IV}

No pretendo en este artículo describir la ulterior (en Hungría ciertamente amplia) difusión del concepto de sociedad civil en Europa Central y Oriental a la luz de las críticas vertidas desde distintos frentes. Tampoco puedo referirme a los detalles sociológicos o políticos del caso húngaro, donde se ha producido un continuo desarrollo de la vida asociativa y de las iniciativas ciudadanas después de la temprana «partificación» de la vida social y donde han surgido nuevos movimientos relevantes desde los años de la transición (tanto en la izquierda como en la derecha). Por el momento, el trabajo empírico de estas tendencias sólo está parcialmente disponible. Aquí me limito a constatar mi impresión sobre el estado actual del discurso sobre la sociedad civil en el caso de Hungría. Me parece que, si bien es cierto que muchos de los que hicieron uso del término como guía para la acción política lo han abandonado, la utilización de la categoría es hoy más amplia que nunca. No pasa un día sin que aparezcan artículos en la prensa diaria discutiendo la situación de la sociedad civil o adoptando el punto de vista de la esfera civil. Los contenidos de los artículos hacen referencia al gobierno local, a asociaciones voluntarias, a organizaciones locales o nacionales que luchan en favor de intereses comunes, o a instituciones culturales o educativas. Parece que existen dos adversarios en los que los actores de la sociedad civil fijan su atención: los partidos políticos que aparentemente intentan monopolizar la vida organizativa, $y$ un gobierno que da muestras de tendencias autoritarias y centralistas. En cada uno de estos casos, el resurgimiento de la sociedad civil y su discurso muestran también 
su lado problemático. Con respecto a los partidos, no siempre está claro si los defensores de la sociedad civil buscan complementar o desplazar a la democracia parlamentaria. Mientras que es cierto que los partidos políticos (que no han creado los canales suficientes para dar entrada en la política a organizaciones jurídicamente privadas) deberian asumir la responsabilidad por la actitud antipolítica de la sociedad, también es cierto que muchas formas de protesta civil han contribuido a una tendencia desafortunada que desprestigia las formas parlamentarias y la competición entre partidos. Al menos en una de sus versiones, el lenguaje de la sociedad civil ha estado al servicio de algunos nuevos populismos, y ello a pesar de que las premisas sociales de una sociedad civil democrática son incompatibles con la política populista.

Las formas de protesta civil son menos ambiguas con respecto al nucvo autoritarismo del gobierno, puesto de manifiesto en Hungría por sus políticas culturales y de medios de comunicación, su actitud con respecto a la disidencia, su enfoque centralizador (en detrimento de los gobiernos locales) y su deseo de evitar al máximo la consulta con organizaciones de intereses. Sin duda, la demanda de menos Estado y menos centralización es totalmente compatible con la necesidad de un gobierno fuerte. Aun asi, el papel actual de Carta Democrática, del Club de Publicidad y del Foro Independiente de Juristas (papeles similares a los desempeñados durante las últimas etapas del régimen comunista) saca a relucir una vcz más la cuestión de si una política basada en la sociedad civil tiene relevancia sólo bajo un gobierno autoritario y es por lo tanto innecesaria después de la consolidación de la democracia liberal.

En nuestra obra pretendíamos demostrar la complementariedad de las políticas de partido y de sociedad civil y la necesidad de concebir la expansión (e incluso defensa) de los derechos humanos y de la democracia como proyectos irrenunciables bajo formas democráticas de gobierno. En lugar de repetir esta tesis, en este momento juzgo más fructífero dotarla de contenido ofrcccciendo una lista de las áreas de análisis más relevantes. Cada uno de estos proyectos, en caso de ser llevado a la práctica, contribuiría a diferenciar analíticamente las dimensiones de estudio de la sociedad civil, y podría servir de ayuda a las tendencias intelectuales y políticas futuras que una vez más desean orientarse hacia la democratización de la sociedad civil.

En este momento éstas son a mi juicio las áreas de estudio más relevantes:

1. El problema de la legitimidad democrática. Necesitamos estudios que exploren la diferencia entre la legitimidad democrática derivada de las precondiciones legales y procedimentales de la política electoral y parlamentaria, y la legitimidad derivada de los «procedimientos» más amplios de la esfera pública democrática en la que participa una amplia red de asociaciones. Necesitamos distinguit empíricamente entre los tipos, niveles y duración del apoyo a los gobiernos a partir de los procedimientos más estrechos de la sociedad política y los más abiertamente democráticos de la sociedad civil. 
2. Los problemas del constitucionalismo. Precisamos explorar el posible papel de la sociedad civil, de sus asociaciones y públicos, en la elaboración de constituciones, en su estabilidad y en el fomento del patriotismo constitucional. Pero también necesitamos examinar, abierta pero críticamente, si (y en qué medida) las constituciones pueden ser también constituciones de la sociedad civil: a) abriendo explícitamente canales para la participación, y b) reforzando las asociaciones civiles' políticamente rclcvantes mediante la regulación de su vida interna y la limitación de las formas de ejercer influencia política.

3. El problema de la maquinaria democrática. Sabemos que la democracia representativa existe bajo formas diferentes. Sin embargo, sabemos más bien poco acerca de las relaciones entre las variedades pluralistas, mayoritarias y de consenso, el presidencialismo y el parlamenarismo, el federalismo y el Estado unitario con respecto al desarrollo de asociaciones y públicos en cuanto componentes activos en la formación de la voluntad popular. Hoy en día existen numerosas combinaciones posibles a partir de las formas disponibles de instituciones democráticas, y necesitamos estudiar las consecuencias que acarrearía en la sociedad civil cada combinación. Éste es un terreno abonado para la comparación empírica y para el diseño de propuestas creativas. En estos momentos, hay pocos argumentos normativos realmente convincentes para optar entre diferentes tipos y combinaciones de democracia. Existen razones para esperar que un punto de vista de la sociedad civil proporcione tales argumentos.

4. La relación entre sociedad civil y sociedad politica. El gobierno local y los partidos políticos nacionales se asemejan (de modo diferente) a las asociaciones de la sociedad civil. En el siglo XIX Tocqueville se refirió a las relaciones entre ambas esferas. Sin embargo, hoy en día no podemos basarnos en el contraste típico-ideal entre una cultura política descentralizada como la nortcamcricana y otra centralizada cuasi-militarmente como la francesa. Necesitamos detectar el impacto de diferentes modelos de gobierno local y de diferentes sistemas de partido en la sociedad civil. En el caso de los gobiernos locales, sería importante documentar las oportunidades políticas que ofrece la descentralización a la vida asociativa. Pero necesitamos asimismo evaluar si el localismo extremo provincializa las instituciones civiles cuya teleología hoy es translocal e incluso transnacional. En el caso de sistemas de partido, debemos examinar el efecto del número de partidos, el grado y tipo de polarización entre ellos, y su estructura organizativa sobre los diferentes modelos de la vida asociativa. Debemos recordar y documentar los efectos de dos formas de desdiferenciación: la polarización partidista de la vida civil posible en contextos multipartidistas y la penetración de la sociedad política por los movimientos y los públicos de la sociedad civil.

5. Debemos una vez más volver al problema de los medios de comunicación de masas como tema preferencial para todos aquellos interesados en una esfera pública democrática. Conocemos gracias a la escuela de Frankfurt (a pesar 
de la unidimensionalidad de sus análisis) los problemas que presentan la comodificación y la comercialización para una comunicación libre. Pero también sabemos que la penetración y el control gubernamental convierten a los medios de comunicación en correas de transmisión política. Estoy convencido de que la proliferación de estudios demostraría que no se trata de elegir entre cultura mercantilizada y propaganda. Propiedad estatal y apoyo corporativo no tienen por qué traducirse en subordinación de la esfera pública. Necesitamos comparar los diferentes modelos disponibles de medios de comunicación al servicio público, y examinar el modo en que las interferencias legales y monetarias del estado y la economía pueden ser absorbidas de modo compatible con el mantenimiento de un público independiente. Existe además la necesidad de estudiar la relación entre públicos profesionalmente diferenciados y las formas de comunicación públicas en las que las propuestas y argumentos lanzados por los expertos pueden ser discutidas sin constreñimientos profesionales. Necesitamos demostrar el posible papel de los medios de comunicación de servicio público en un público civil no diferenciado.

6. Por último, debemos examinar el problema de la globalización de la sociedad civil. Evidentemente, en nuestros días numerosas organizaciones relevantes de la sociedad civil son globales por definición. Esto es especialmente cierto en el caso de las organizaciones dedicadas al respeto de los parámetros básicos de la sociedad civil, como por ejemplo los derechos humanos. De modo similar, todos los públicos civiles genuinos son hoy en día de carácter internacional. Prccisamos estudiar las relaciones de las asociaciones y públicos globales con las sociedades y culturas locales, así como con los estados nacionales y las organizaciones gubernamentales internacionales.

No sugiero de ningún modo que estas seis áreas de investigación sean las únicas relevantes para quienes desean convertir la teoría de la sociedad civil en un conjunto más diferenciado de instrumentos analíticos, intelectualmente más plausibles para las décadas venideras. De lo que sí estoy seguro es de que hallazgos favorables en estas áreas se traducirán en un avance en la legitimación del concepto de sociedad civil en el campo de las ciencias sociales. De hecho, hallazgos positivos en cualquiera de estas áreas sería una gran contribución para quienes están comprometidos en la política de la sociedad civil y desean comprender mejor el significado de su propia acción. 


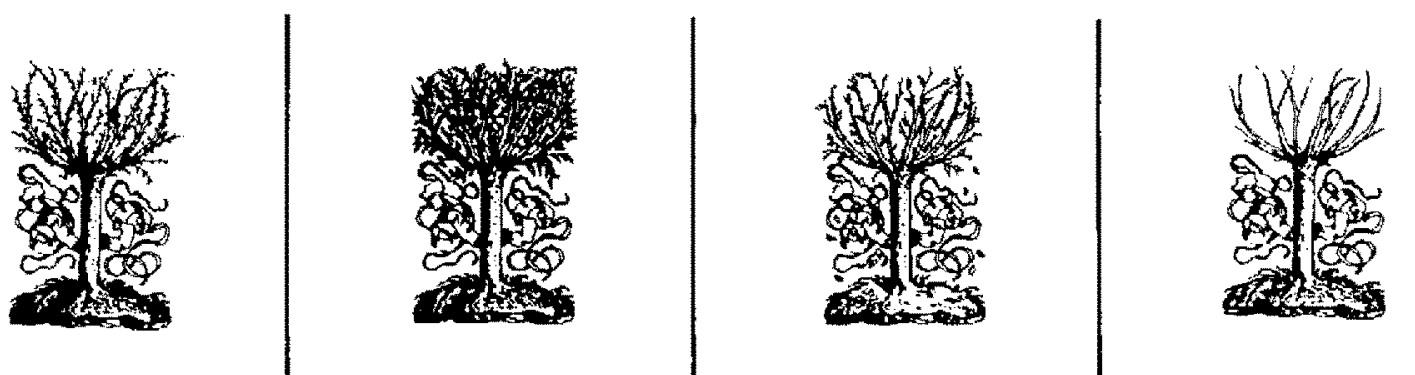

\section{CONSEJO|SUPERIOR DE INVESTIGACIONES CIENTIFICAS}

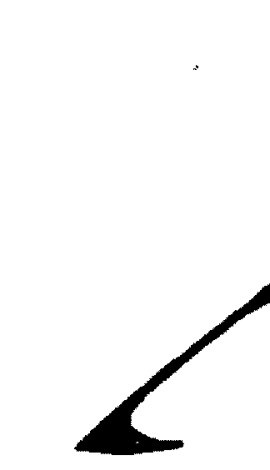

FEBRERO 1996

Francisco Mora:

Neurociencla y Pensamitento.

ntrodusción.

Lose Maria Delgado Garcia: ipara que mover los dios si ya movemos cabeca?

Aberto Ferrus:

Cefebray genoma: cos lecturas paratelas.

Antonio G, Garcie y tuis Ganda: Biogumímica y farmacologla de la neufotansmicican sinaptica.

Manted silito Sarmoedro: Plasticidad neural: del aprendizaja a la reparacion de lesionos.

Jesuis Fiorer:

cerebro, atracción y deseo.

\section{Luis Puteles:}

Desarotlo y plasticidad neurales.

implicaciones para la teoria

materialssta emergente de is mente.

Franciseo Mora

Neurociencias: ¿Hacia una nueva

concepcion del nothre?

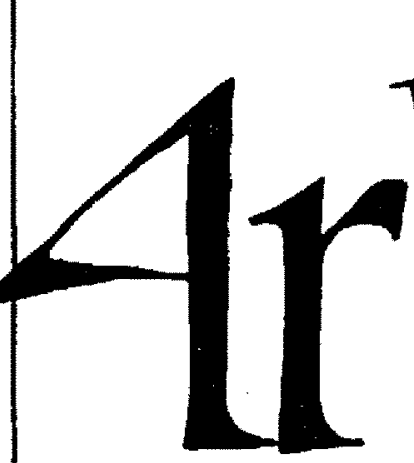

MARZO 1995

Foberto Morbno. Ana Romera, Fernando Redrajo:

Lo Fecupetacion od to

instrumentación cientificontristrica del Consejo Superior de

investigaciones Cientificas.

Enilo Muñoz.

Agricultura y Biadiversidad

Biotecnologla y su relacton

conflictiva con el medio ambiante.

Ramón Lapiedra:

Psicoanatisis y ciencia: Ires

curstiones epistemologicas.

Javion Arsoll:

Feslidad y tapresentacion mediante sisternas dinárnicos.

Pedro Garaia Barrano

El hospital Generat de Madrid. Su primer reglamento (1589)

Ralas E. Tarragó El martiplo liberal autonimista y Josa Manti.

\section{ciencia}

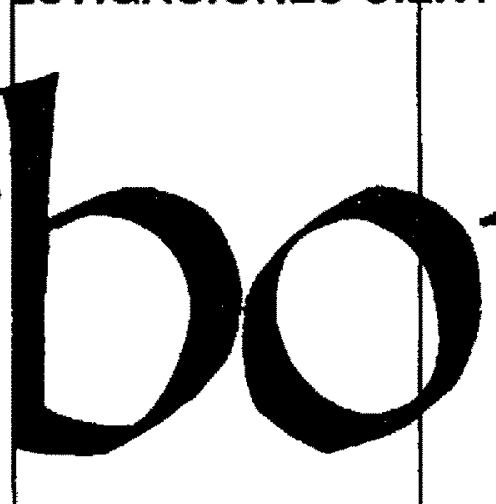

\section{ABRIL-MAYO 1996}

EN TORHO A CIENCA Y TECHICA EN LA SOCKOAAD ESPANOLL 4 OE $L O S$ SIGLOS XVI Y XII OE JOSE W'LOPEZ PANERO

Jose Hantut Sthchez Ron: "Presentaciótin.

Losé Maris Loper Pif̌rero: aTradición y discontinutuad en España de la historiografia de la cienclan.

Pedro Lain Enfrafgo: "Jose Waria López Piñen y la historia de la ciencia essuañolan.

F. vaver puerto sanmento: wh clásico contenporáneos.

Mariano Exteban Piñoto: mCiencia y técnica... fuarte y guia para la investización sobre la Ciencia y la Tecrica en el Sigfo de Oro.

Thomas F. Gllck: Lopez Piñero y Foben Nerton: Ciencia, If́chica, motivación, decadencian,

Lus Garcla Bailester; +Naturaleza y ciencia an la Castila del siglo XIII. cer oritenes de una trading Los orgenes de una tradicion: los Shida mancistano y dominico do Santiago

Joo Arrizabalaga: uprectica y teria en la medicina universitaria de finatos del siglo XV. El tratarilento det mal hancas en la corte papal de Alcjandro VI Borgiax.

Pakal Chatuan; "Lopez Piñeroy la histotia natura: Las apontaciones de Fancisco Hermandez.

Victor Navano Brorons: en la España del siglo XVI:

El cultivo de las disciplinas

risico-matematicas:.

Antonio Dominguez Drtz; :La inquisicion y los liustrados semillanos: Las ticencias para leer libros prohitidos.

pensamiento

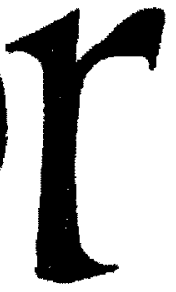

DIRECTOR

Magus' Anget Oumbatila

DIFECTOR ADJUNTO

Jose ax sancher for

REDACCION

VIrUlia $\theta$-2BOOS MAORID Teter. 에 561655 i

SUSCRIPCIONES

Servico de Publicaciones de C.S.iC.

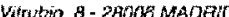
Telef. (91) 5612833 